
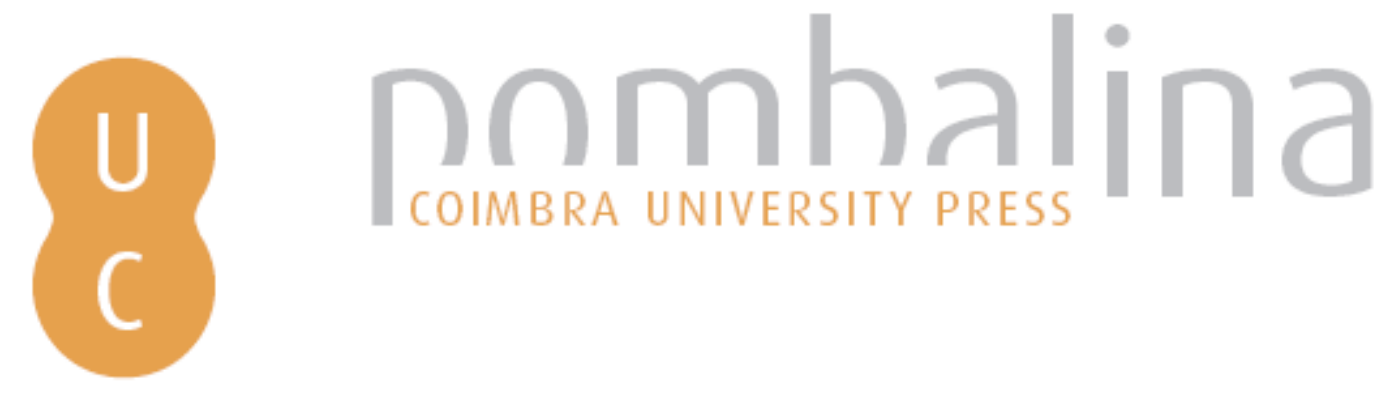

\title{
A época de Miguel Bombarda na conceptualização da urgência pré-hospitalar
}

Autor(es): $\quad$ Bandeira, Romero; Teiga, Céu; Gandra, Sara; Pereira-Pinto, Sandra

Publicado por: Imprensa da Universidade de Coimbra

URL

persistente:

URI:http://hdl.handle.net/10316.2/32305

DOI:

DOI:http://dx.doi.org/10.14195/978-989-26-0362-9_6

Accessed : $\quad$ 26-Apr-2023 13:02:40

A navegação consulta e descarregamento dos títulos inseridos nas Bibliotecas Digitais UC Digitalis, UC Pombalina e UC Impactum, pressupõem a aceitação plena e sem reservas dos Termos e Condições de Uso destas Bibliotecas Digitais, disponíveis em https://digitalis.uc.pt/pt-pt/termos.

Conforme exposto nos referidos Termos e Condições de Uso, o descarregamento de títulos de acesso restrito requer uma licença válida de autorização devendo o utilizador aceder ao(s) documento(s) a partir de um endereço de IP da instituição detentora da supramencionada licença.

Ao utilizador é apenas permitido o descarregamento para uso pessoal, pelo que o emprego do(s) título(s) descarregado(s) para outro fim, designadamente comercial, carece de autorização do respetivo autor ou editor da obra.

Na medida em que todas as obras da UC Digitalis se encontram protegidas pelo Código do Direito de Autor e Direitos Conexos e demais legislação aplicável, toda a cópia, parcial ou total, deste documento, nos casos em que é legalmente admitida, deverá conter ou fazer-se acompanhar por este aviso. 
Ana Leonar Pereira Jםão Rui Pita [ Coordenaçä̃ ]

\section{Miguel Bomberda e as singularidades de uma época}

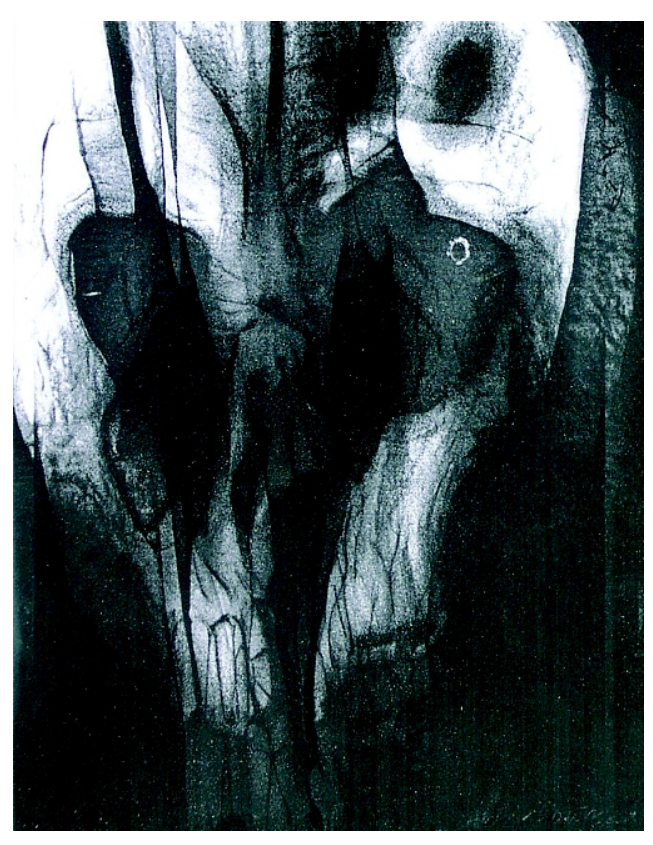


(Página deixada propositadamente em branco) 
Ana Leonor Pereira

João Rui Pita

(Coordenação)

\title{
FOLHA DE ROSTO
}

\author{
Miguel Bombarda (1851-1910)
}

a as singularidades de uma época 


\section{Coordenação Científica da Colecção Ciências e Culturas}

João Rui Pita e Ana Leonor Pereira

Os originais enviados são sujeitos a apreciação científica por referees

\section{Coordenação Editorial}

Maria João Padez Ferreira de Castro

\section{Edição}

Imprensa da Universidade de Coimbra

Email: impresauc@ci.uc.pt

URL: http://www.imp.uc.pt • Normas de publicação de colecções

Design

António Barros

Pré-Impressão

António Resende

Imprensa da Universidade de Coimbra

Capa

António Dantas. Sem título, 2002. Col. António Barros. Coimbra

Impressão e Acabamento

SerSilito • Maia

\section{ISBN}

978-989-8074-11-9

\section{Depósito Legal}

Obra publicada com a colaboração de:
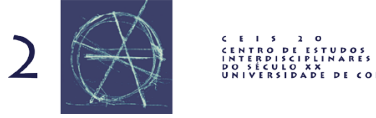

Obra publicada com o apoio de:

FCT Fundação para a Ciência e a Tecnologia

MINISTÉRIO DA CIÊNCIA, TECNOLOGIA E ENSINO SUPERIOR Portugal

Programa Operacional Ciência, Tecnologia, Inovação do Quadro Comunitário de Apoio III

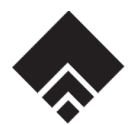

Fundaçāo Eng. António de Almeida

(C) Agosto 2006, Imprensa da Universidade de Coimbra 
Romero Bandeira* ; Céu Teiga** ${ }^{* *}$ Sara Gandra** ; Sandra Pereira-Pinto***

* Inst. Ciências Biomédicas Abel Salazar (Univ. Porto) e CEIS20, Univ. Coimbra, Portugal

** Al. Mestrado em Medicina de Catástrofe, ICBAS, Universidade do Porto, Portugal

*** Mon. História da Medicina, ICBAS, Universidade do Porto, Portugal

\section{A época de Miguel Bombarda na conceptualizaÇão DA URGÊNCIA PRÉ-HOSPITALAR}

\section{Introdução}

O conceito de urgência extra-hospitalar individual e colectivo desenvolve-se e inicia a sua consolidação neste período, 1880-1910.

O aparecimento do Rx (1895), da indústria dos plásticos (1880), da telegrafia sem fios (1892), do voo do helicóptero (1907), da câmara de filmar (1888), do radiotelefone (1901), dos grupos sanguíneos (1980). Durante o cerco de Paris em 1870, 160 civis foram evacuados por balóes de ar quente tendo, ao que parece, todos sobrevivido à novel e insólita evacuação (Wingert, 1977).

No Porto, em 1910, Pedro Vitorino Ribeiro, com uma brilhante tese intitulada Socorros de Urgência (Breves Notas) apresentada à Faculdade de Medicina do Porto, opina esclarecidamente acerca da Urgência Extra-Hospitalar.

Sem o statu quo ante cientifico tecnológico adquirido durante a época de Bombarda, não seria possível falar-se de Suporte Avançado de Vida, equacionado no seu sentido mais amplo a nível do domínio da urgência extra-hospitalar.

Júlio Dinis (Cruz 2002) nas suas proposiçōes de defesa de dissertação a apresentar à Escola Médico-Cirúrgica do Porto em 1861 enunciou que: $o$ ensino clínico feito por meio da prática nos Hospitais é incompleto

Os quatro Cavaleiros do Apocalipse imortalizados na celebre xilogravura de Albrecht Dürer de 1498 (Aris, 2002) têm um denominador comum que é a própria Morte. Se no instante zero da vida todos os homens são iguais, ao invés do postulado para o nascimento, múltiplos foram os mecanismos, induzidos uns e criados outros, no sentido de que aquele efémero instante fosse retardado; de tal jeito e forma que foi criada a palavra «imortal»!

A Medicina a esse estudo se entregou afanosamente aportando para esse momento todos os cuidados possíveis tendo-se desenvolvido o conceito de urgência médica extrahospitalar com a intervenção a nível das vítimas individuais ou mesmo multivitimas.

O braço armado de um dos cavaleiros de Albrecht Dürer é o terrorismo forma actualizada e versátil da Guerra na sua versão mais execrável. Guerra é também sinónimo de feridos e mortes. E, na Humanidade, se uns se comprazem em alardear os seus malefícios outros procuram por todos os meios ao seu alcance atenua-los. 
A situação paradoxal que hoje se coloca em termos de valer a todos e ao mesmo tempo teve a sua expressão máxima no dia 11 de Setembro de 2001 a nível dos EUA. Não só porque se tratasse do maior número de vítimas e nas circunstâncias mais inusitadas, mas pela transmissão mediática de imagens e por se tratar do país mais moderno do Mundo porque vítimas de atentado terrorista sempre houve, quer ele se produza sob a porta de Brandenburg em Berlim, num recôndito pueblo do País Vasco ou numa longínqua paragem oriental.

No dizer de José António Baptista (1996) a o período em que viveu D. Carlos I (1863-1908) pode ser considerada uma época renascentista no domínio dos estudos científicos em Portugal sem infelizmente ter tido a repercussão prática desejável, fruto da "posição cultural de uma sociedade menos inimiga do que indiferente». Corroboramos por inteiro esta opinião sendo dela exemplo paradigmático o que se passou no âmbito da medicina como aquilataremos no desenvolvimento deste trabalho.

A época de Miguel Bombarda é charneira porque nos seus últimos anos, indubitavelmente que a urgência médica extra hospitalar foi buscar conhecimentos e experiência à Medicina de Guerra, trazendo-a para o terreno não só na univítima como nas multivitimas. Podemos mesmo aventar que foi a época dourada no estabelecimento e generalização máxima dos princípios e premissas do socorro longe dos muros da alvenaria hospitalar.

\section{A Medicina de Guerra}

A Medicina de urgência caracteriza-se por uma necessidade imperiosa de prestar socorros sem delongas. Tal como Emmanuelli X e Emmanuelli J (1996) nos transmitem ela radica-se na Medicina Geral com base na experiência prodigalizada pela Medicina de Guerra e o desenvolvimento da anestesia e da reanimação. Se, como médico, Ambroise Paré é considerado no séc. XVI o pai do soldado e com ele a medicina da frente de batalha se começa a implementar e a desenvolver é, porém, com os náufragos, em que o afogamento é considerado a primeira causa de mortalidade acidental e quando os poderes públicos se decidam a intervir a nível da sociedade civil. A tremenda incompetência do serviço de saúde militar traduzia-se em resultados catastróficos.

$\mathrm{Na}$ sua tese de doutoramento Bandeira (1995) relata-nos:

As Campanhas Napoleónicas são disso um exemplo claro. Sobressaindo como introdutor de novos métodos científicos e técnicas que revolucionaram a época em que foram estabelecidas, e que ainda hoje nos influenciam, avulta o Barão Jean Dominique Larrey, que se tornou um paradigma no relacionamento médico-doente e que na qualidade de Médico - Chefe dos exércitos de Napoleão, este, tivesse escrito no seu testamento: "Lego ao Cirurgião em Chefe, Larrey, cem mil francos. É o homem mais virtuoso que jamais conheci»

Uma notícia necrológica foi publicada no tomo XVIII do mês de Julho de 1843 do Jornal da Sociedade de Ciências Médicas de Lisboa, dado ele ter sido seu sócio honorário.

Ao rebentar a guerra de 1792, é colocado no exército do Reno, com as funções de Adjunto do Cirurgiāo Mor, sendo verdadeiramente a partir desta altura que se torna 
inovador, em matéria de saúde militar. Profundamente preocupado com as condições em que eram socorridos e tratados os militares atingidos na frente de batalha, tornam-se célebres os seus desaguisados com a intendência militar, com efeito não existia em, da mesma forma que no resto da Europa, Serviço de Saúde independente no seio da organização militar (a autonomia do Corpo de Saúde Militar data em França unicamente de 1917).

Já havia sido criado por Percy um grupo de auxiliares sanitários e respectivas ambulâncias cujo fim era prestar os primeiros socorros e fazer o levantamento de feridos. A ambulância do barão Percy chamada wurst (da palavra alemã salsicha) porque os passageiros estavam ás cavaleiras sobre uma caixa de material que fazia lembrar uma salsicha; este equipamento imaginado por Percy, muito rápido e atrelado por seis cavalos, transportava 8 cirurgióes e podia conter nos seus cofres socorros para 1200 feridos. Antes de Larrey os cirurgiōes e as suas pesadas ambulâncias - cuja distribuição era decidida no gabinete do Intendente - não chegavam senão 24 horas ou 36 horas após o combate, segundo diz o próprio Larrey nas suas memórias, não restando outra alternativa senão reunir os cadáveres e os moribundos.

Criou, pois, as célebres ambulâncias volantes ligeiras, as quais passaram a oferecer um transporte mais rápido e eficaz, possibilitando que os soldados recebessem pouco depois de feridos, por vezes mesmo debaixo de fogo os socorros devidos. No entanto as suas ambulâncias que foram inspiradas nas baterias volantes de artilharia que rapidamente podiam ser mudadas de posição, permitiam igualmente o destacamento para os lugares necessários, durante a batalha, de pessoal e material requeridos quer para tratamentos definitivos, quer para operaçôes. Foi pois, o primeiro cirurgiāo que levou o quirófano às linhas de batalha devendo ser posta em evidência a coragem dos soldados que valentemente enfrentavam o bisturi, tão grande era a confiança que depositavam no Cirurgião - Chefe do Grande Exército.

A nova Cirurgia Militar para além do tratamento dos feridos e dos enfermos compreendia a organização do transporte dos feridos e dos enfermos e da sua assistência facultativa na frente da batalha, o abastecimento das enfermarias e hospitais de campanha, a formação técnica do pessoal sanitário auxiliar, inclusivamente a adopção de medidas preventivas baseadas em estudos epidemiológicos.

Os decretos de 18 de Setembro de 1824, de 1 de Abril de 1831 e de 3 de Maio de 1832 consagram a submissão do Serviço de Saúde ao da Intendência mas reorganizam os Hospitais Militares e criam o Corpo de enfermeiros pedidos desde há longa data por Larrey.

Os batalhōes de Saúde perpetuaram durante a II Guerra Mundial no Serviço de Saúde da frente o que tinham sido os Auto-chir de 1915 e as ambulâncias volantes de Percy e Larrey

Imaginou o transporte dos feridos no dorso do camelo na Campanha da Síria, «tratava-se de usar os camelos, única montada do país. Consequentemente mandei construir cestos, dois por camelo dispostos em forma de berço, que o animal carregava de cada lado da sua bossa suspenso por correias elásticas de modo a transportar um ferido deitado a todo o comprimento».

Esteve presente num total de 26 campanhas como ele próprio diz no prefácio da sua "Clinique Chirurgicale» e não 25 como habitualmente se encontra citado; em 60 batalhas e 400 combates, tendo sido ferido três vezes. 
Em Conclusão, foi o percursor do actual conceito de MASH (Mobile Army Surgical Hospital).

As «Filles de la Charité» tal como se encarregavam de grande parte dos estabelecimentos hospitalares civis também o faziam para os militares.

Foram oficialmente integradas nos hospitais militares através do Regulamento do Serviço de Saúde Francês de 31 de Agosto de 1865 embora, seguindo o exemplo do seu patrono S. Vicente Paulo em 1658, acompanhavam desde há muito o Exercito nos campos de batalha (Guillermand 1988).

Um outro conflito, a Guerra da Itália que iria opor Franceses e Sardos aos Austríacos alguns anos depois, traduzir-se-ia por um menor tempo de operaçōes mas por uma gravidade acrescida, tendo atingido o zénite no campo de batalha de Solferino. Para se ter uma ideia das perdas, o Exercito Francês teve 3409 mortos ou desaparecidos e 9407 feridos, o Sardão 1949 mortos ou desaparecidos e 3405 feridos, o Austríaco teve perdas na casa dos 20000 homens (Guillermand 1988)

Foi este cenário de Guerra que gerou a ideia da Cruz Vermelha.

Conforme nos mostra Laffont et al. (1959) ela nasceu do horror da guerra, que veio suscitar neste caso uma iniciativa pacifica de envergadura internacional. Henri Dunant escreveu "O Sol do dia 25 de Junho de 1859 iluminou em Solferino um dos espectáculos mais horríveis que se possam apresentar à imaginação. O campo de batalha está juncado de cadáveres, de homens e de cavalos».

Em Portugal e conforme nos descreve Álvaro Rodrigues (1986) o primeiro bacharel formado pela Universidade de Coimbra entrou para o Corpo dos Cirurgiōes Militares em 1846, tendo-se iniciado no ano seguinte as primeiras anestesias por meio de um aparelho improvisado, o eterizador.

Conforme Ferreira de Mira (1947) nos relata Cunha Belém em 1879 publica um trabalho sobre medicina militar no campo de batalha, bem como um estudo sobre o transporte de feridos. Desnecessário se torna encarecer que a publicação deste tipo de experiências torna plausível a sua aplicação à sociedade civil, o que foi um facto, como a seguir veremos.

\section{Epidemias}

A segunda metade do Séc. XIX trouxe à Medicina conceitos inovadores: o exame clínico, com a actualização de exames paraclínicos laboratoriais e a utilização de novos aparelhos, indo desde a introdução dum termómetro médico, Wunderlich, 1856, até ao registo no fim do século da actividade eléctrica cardíaca por Einhoven. No estudo das células avulta o nome de Virchow e na fisiologia o de Claude Bernard. Pasteur e Koch na Microbiologia (Gonzalès 1997).

Mas a acção no limitar das hemorragias, na anestesia e na luta contra a infecção, ao serem estabelecidas as noções de assepsia e antissepsia associadas à introdução de novos medicamentos, conduziram à emergência duma nova filosofia médica apoiada em tecnologia médica que permitiu formular uma intervenção extra-hospitalar.

Tal como Dürer nos representou para a época em que viveu, as epidemias continuaram a fazer repercutir em todos os povos a sua influência catastrófica na Sociedade. Portugal a elas não ficou indemne e a epidemias da cólera de Lisboa em 1894 e da peste 
do Porto de 1899 foram marcantes. Torres-Pereira (1896) refere-nos igualmente que em 1893 se assinala como o primeiro ano da luta anti-rábica em Portugal conforme no-lo descreveram Câmara Pestana e Anibal Betteucourt em 1894. De acordo com o mesmo autor, em Portugal, só existiam em 1896 duas associações restritas a médicos, a Sociedade de Ciências Médicas de Lisboa e a União Médica do Porto.

Manuel Bento de Sousa na epidemia que assolou Lisboa em 1894, que alguns autores classificaram de colerina, preconizou o uso de Hospitais - Tenda. (Ferreira-de-Mira 1947).

Obviamente que se tratava de um avanço para a época e muito especialmente em Portugal, na medida em que o conceito de hospital se encontrava arreigado aos princípios clássicos de construção para aqueles edifícios, e só o aparecimento abrupto de multivítimas, associado a um tempo bem delimitado no tratamento das mesmas condicionou a equação do seu uso. Foram o prenúncio dos actuais Postos Médicos Avançados (PMA) e dos Centros Médicos de Evacuação (CME).

No dobrar do Séc. XIX, dois médicos portugueses, autênticos interventores no terreno, tal como hoje os denominaríamos, sofreram o azorrague da peste. O notável bacteriólogo Câmara Pestana, que morre em 15 de Novembro de 1899 ao ser contagiado pela doença no Porto, com 36 anos apenas e Ricardo Jorge que se viu obrigado a abandonar a cidade Invicta, face à hostilidade desencadeada contra a sua pessoa, uma vez que a brilhante e esclarecida acção científica desenvolvida no combate à peste colidia fortemente com interesses conómicos vigentes.

\section{A problemática do socorro extra-hospitalar}

Como outros hospitais em Portugal o Hospital Geral de Santo António sempre se viu envolvido em acções de Urgência Extra- hospitalar. Como Hospital Universitário foi escola de muitos clínicos e proeminentes figuras, de entre eles o Dr. Joaquim Pedro Vitorino Ribeiro, que apresentou a sua dissertação em 1910 denominada «Socorros de Urgência(Breves Notas)» onde relatou a necessidade e as vantagens da organização dos serviços de cuidados de emergência. (Bandeira 1995):

«Apresentada como dissertação inaugural à Faculdade de Medicina do Porto em 1910, a doutrina nela expendida é duma actualidade marcante.

Constituída por 58 páginas de texto, logo nas palavras prévias o autor escreveu:

«O desastre sucedido num diário desta cidade, onde em um aluimento foram arrastadas dezenas de pessoas da altura de um andar. Contaram-se numerosos feridos e dez mortos.

Acorreram prestes os bombeiros, libertando os desventurados do pavoroso amontoado em que jaziam. Sucessivamente iam sendo transportados em macas para o hospital os que não podiam caminhar por seu pé. Ferimentos, asphixias, fracturas, tudo foi, se bem que mal, a caminho da misericórdia, numa extensa caravana desoladora. Eis a questão. Se houvesse um serviço de socorro organizado, com pessoal idóneo, médicos e auxiliares, uma selecção teria sido feita no momento, e não haveria por certo a registar um número tão elevado de mortos.

Aventarei mesmo que todos escapariam... algumas das vitimas, as sufocadas por asphixia, deveriam ser socorridas imediatamente nas casas próximas. 
Matou-as a longa caminhada para o hospital. As conclusões das autópsias o confirmam: das dez vitimas, nove morreram devido a asphixia por sufocação e uma pela hemorragia proveniente dos ferimentos.»

E mais adiante "Proclamar, pois, as sumas vantagens da organização dos socorros médicos nos sinistros, do estabelecimento de postos nas margens, fluviaes e marítimas, e da vulgarização dos socorros de urgência, taes são os intentos déste desprendido tentamen que a lei determinou, mas que a razão dos factos concebeu, embora precipitadamente, atabalhoadamente...»

O I Capitulo intitula-se «Necessidade e vantagens do serviço de pronto socorro. Sua organização em diversos países» do qual se extracta:

"Contudo, no sentido de socorros de urgência, nenhuma tentativa séria foi ainda feita. Os estabelecimentos hospitalares que tentam suprir esta falta são, sob tal ponto de vista, o que todos sabem - insuficientes. A ineficácia da sua acção resulta simplesmente de ser - demasiado tardia.

Tal sucede aqui, no Hospital de Santo António. Único oásis no meio de um enorme deserto, muitas vezes a sua Iympha nem chega a humedecer os lábios d'aqueles que o demandam.

O último sopro de vida extinguiu-se no caminho. Concretizemos. Afoga-se uma criatura no Douro, e por qualquer meio é agarrada e conduzida a terra. Que é uso fazer-se em tal conjectura? Apitar, para acudir a polícia que manda buscar uma maca à esquadra mais próxima e faz transportar, com uma duvidosa ligeireza, o desventurado para o Hospital da Misericórdia.»

\section{No fim deste capitulo escreveu:}

«Taes são, singelamente esboçados, os serviços de pronto socorro nos variados países que lhes têm dedicado o interesse que merecem. Muito seria para estimar que alguma coisa n'este sentido fosse tentada em Portugal, não esquecendo também a divulgação dos cuidados de urgência que é d'uma provadíssima utilidade.»

A visão do problema é tão lúcida que carece de qualquer tipo de comentário.»

Sem sombra de dúvida que o socorro urgente extra-hospitalar junto da população foi cometido em larguíssima escala aos Bombeiros, mais do que a qualquer outra Instituição o que é facilmente compreensível se atentarmos a que os Corpos de Bombeiros Voluntários dependem fundamentalmente de Associações Humanitárias as quais não só são uma emanação das necessidades das populaçôes a nível dos Municípios, mas também por que estão espalhadas por todo o País.

Acresce ainda o facto de que a sua implementação nos principais núcleos urbanos se fez rapidamente sobretudo na época em que estamos a tratar.

Ao ler o trabalho de Agostinho (1995) a nossa atenção foi chamada para um documento intitulado «Da ambulância» e que é um fac simile do art. 56 dos Estatutos da AHBV de Ponte de Lima - 1887. Com base no mesmo trabalho aquilatamos o grande desenvolvimento que tiveram as Secções de ambulâncias entre 1878 e 1920.

Em 1878 os BV de Santarém, possuíram a sua primeira ambulância, e em 1910 os B.V. da Figueira da Foz e os de Portalegre criam a sua. Em 12 de Outubro de 1897 os Bombeiros Voluntários do Porto já teriam o seu Corpo de Saúde, mas em 1885 os B.V. de Guimarães puseram a sua ambulância ao Serviço da autoridade sanitária perante uma epidemia de cólera. 
Esta estrutura sanitária tinha por missão aquilo que hoje denominamos por medicina ocupacional, além da intervenção no terreno; "Na generalidade dos casos, as Secçôes de Ambulância eram integradas por médicos, chamados facultativos, farmacêuticos e pessoal do respectivo corpo de bombeiros, a quem eram ministrados ensinamentos específicos para a prática dos curativos e socorro. Aspirantes e praças para auxilio das facultativas eram nomeados pelo respectivo comandante» (Agostinho 1995).

As acçóes do socorro extra-hospitalar torna-se-iam impossíveis se da parte da indústria farmacêutica não houvesse um desenvolvimento paralelo. Tal como Rui Pita (1998) no-lo transmite, a indústria farmacêutica incrementou a sua actividade no final do Séc. XIX com o aparecimento de novos laboratórios liderados por destacados farmacêuticos. Igualmente é de encomiar a produção científica farmacêutica, como diz aquele autor, na segunda metade do Séc. XIX e nos primeiros anos do presente.

\section{Reflexões Conclusivas}

A cem anos de distância de uma época a todos os títulos brilhante, o respeito pela vida humana foi equacionado e forjado de tal forma que ainda hoje o vivemos, e, acicatados de tal ordem que em Portugal apesar de nos separar um abismo não só qualitativo mas também quantitativo de outros países um grupo de profissionais do socorro médicos, enfermeiros bombeiros e organismos congéneres esforçam-se a todo o transe para colmatar falhas às quais o Estado não consegue dar resposta criando cidadão de segunda no interior e de primeira nalgumas localidades do Litoral.

Porém, no âmbito do socorro extra-hospitalar a época de Miguel Bombarda continua, como uma luz bruxuleante, a iluminar-nos e a indicar teimosamente o caminho a seguir.

Procuremos fazê-lo.

\section{BIBLIOGRAFIA}

Agostinho E. (1995) Desenvolvimento do Serviço de Saúde nos Bombeiros Portugueses. In: Herminio-Santos F. (ed.). Bombeiros Portugueses - Dois Séculos de História (1395-1995), Vol I, Serviço Nacional de Bombeiros Portugueses e Liga dos Bombeiros Portugueses, Lisboa pp. 43-60.

ARIS A. (2002) Medicina en la Pintura. Lunwerg Editores, Madrid.

BANDEIRA R. (1995) Medicina de Catástrofe - Da Exemplificação Histórica à Iatroética. Tese de Doutoramento, ICBAS. Porto.

Baptista, A. M. (1996) A primeira idade da Ciência. Gradiva, Lisboa

Cruz, L. (2002) Júlio Dinis, Biografia. Quetzal Editores, Lisboa

Emmanuelli, X. e Emmanuelli J. (1996) Au Secours de la Vie, La medicine d'urgence. Ed. Gallimard. Evreux.

Ferreira de Mira, M. (1947) História da Medicina Portuguesa. Ed. Empresa Nacional de Publicidade. Lisboa.

GONZALÈs, J. (1997) Initiation à l'histoire de la Medicine. Editores Heures de France. Thoiry.

Pita, J. R. (1998) História da Farmácia. Ordem dos Farmaceuticos - Sec. Reg. Coimbra, Minerva, Coimbra. 
Rodrigues, A. (1986) Desenvolvimento da Cirurgia Portuguesa até aos finais do Séc. XIX. In: Vasconcellos-Marques A. (ed.) História e Desenvolvimento da Ciência em Portugal, Vol. I. Academia das Ciências de Lisboa, Lisboa pp. 506-527.

Torres-Pereira, A. (1986) História e Desenvolvimento da Bacteriologia em Portugal. In: VasconcellosMarques A. (ed.) História e Desenvolvimento da Ciência em Portugal, Vol. I, Academia das Ciências de Lisboa, Lisboa pp. 529-575.

Wingert, W. (1977) Setting Standards for Critical Care Transport: Fitz - Gibbon's Law Revisited. In: Hackel A. (ed) Internacional Anesthesiology Clinics, Vol, XXV, Critical Care Transport. Litle, Brown \& Co, Boston, pp. 139-157.

Resumo - O conceito de urgência extra-hospitalar individual e colectivo desenvolve-se e inicia a sua consolidação neste período (1880-1910).

O aparecimento do $\mathrm{Rx}$ (1895), da indústria dos plásticos (1880), da telegrafia sem fios (1892), do voo de helicóptero (1907), da câmara de filmar (1888), do radiotelefone (1901), dos grupos sanguíneos (1900); durante o cerco de Paris em 1870, 160 civis foram evacuados por balóes de ar quente tendo, ao que parece, todos sobrevivido à novel e insólita evacuação. No Porto, em 1910, Pedro Vitorino Ribeiro, com uma brilhante tese intitulada Socorros de Urgência (Breves Notas) apresentada à Faculdade de Medicina do Porto opina esclarecidamente acerca da Urgência extra-hospitalar.

Sem o statu quo ante científico-tecnológico adquirido durante a época de Bombarda, não seria possível hoje falar-se de suporte avançado à vida, equacionado no seu sentido mais amplo a nível do domínio da urgência extra-hospitalar.

Abstract - The concept of individual and collective extra-hospital emergency was developed and began its consolidation during this period (1880-1910).

The emergence of the X-Ray (1895), the plastics industry (1880), wireless telegraphy, the helicopter (1907), the camera (1888), the radiotelephone (1901), blood groups (1880). In 1870, 160 civilians were evacuated by heated air balloons during the siege in Paris, having apparently survived to this unusual and extraordinary evacuation. In 1910, Pedro Vitorino Ribeiro presents enlightened arguments about extrahospital emergency in a brilliant thesis entitled 'Socorros de Urgência (Brief Notes)' and presented to the Faculty of Medicine in Oporto.

Without the scientific-technological statu quo ante acquired during the epoch of Bombarda, it would not be possible to talk about advanced support to life today, which consists of extra-hospital emergency in the largest sense. 
(Página deixada propositadamente em branco) 


\section{Colecção \\ Ciências e Culturas \\ Cuimbra 2006}

